\title{
Radial Collateral Ligament Injury of the Thumb Metacarpophalangeal Joint
}

\author{
Devi Prasad Mohapatra1,๑ Sunitha Vellathussery Chakkalakkoombil ${ }^{2}$
}

\author{
${ }^{1}$ Department of Plastic Surgery, JIPMER, Dhanvantri Nagar, \\ Gorimedu, Puducherry, India \\ 2Department of Radiodiagnosis, JIPMER, Dhanvantri Nagar, \\ Gorimedu, Puducherry, India
}

Indian J Plast Surg:2020;53:457-458

Radial collateral ligament injuries of the thumb metacarpophalangeal (MCP) joint, associated with partial or complete tear of the ligament, are uncommon injuries of the thumb when compared with ulnar collateral ligament injuries. Early detection and appropriate treatment of these injuries will help in preventing attenuation of the ligament and chronic instability of the thumb. A 30-year-old female presents with complaints of localized pain, aggravated on movements, over the region of proximal left thumb of 3 weeks duration. She did not give a history of trauma to the part; however, detailed history analysis revealed that she had an episode of trivial trauma to the thumb while trying to park her motorbike on its central stand that needed pulling the bike with her left hand. Clinical examination of the left hand revealed an

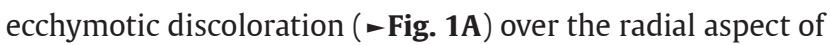
left thumb MCP joint with mild edema and tenderness over the region. Any attempt to actively oppose the thumb to left little fingertip increased the pain over the MCP joint. Stress testing of the left thumb increased the tenderness over the thumb MCP joint. A clinical diagnosis of thumb sprain with probable radial collateral ligament injury was made and the lady advised 1 week of rest to the part with analgesics and crepe bandage application. When the pain did not get relieved at the end of 1 week, she was subjected to a magnetic resonance imaging (MRI) scan of the thumb to assess the radial collateral ligament. MRI revealed high signal intensity involving the abductor pollicis brevis/radial collateral ligament complex of the thumb and in the soft tissues around flexor pollicis longus tendon, indicating edema suggestive of posttraumatic inflammation without discontinuity in the radial collateral ligament ( $\mathbf{- F i g}$. $\mathbf{2 A}$ and $\mathbf{B}$ ). The patient was advised splint to the thumb and strict rest for 3 weeks more. At the end of 3 weeks, the pain was relieved, and she could start her routine activities.

\begin{abstract}
Address for correspondence Devi Prasad Mohapatra, MCh, Department of Plastic Surgery, 4th floor SSB, JIPMER,

Puducherry, 605006, India (e-mail: devimohapatra1@gmail.com).
\end{abstract}

Collateral ligaments provide intrinsic stability to ulnar and radial side of the thumb MCP. They get stretched during flexion of the MCP joint and are lax during extension of the joint. Acute collateral ligament injuries may be seen during sporting activities with ulnar collateral ligament injuries being more frequent than radial collateral injuries. ${ }^{1}$ The injuries are graded as Grade I (injury without tears in the ligament), Grade II (partial disruption), and Grade III (complete disruption). In our patient, the mechanism of injury was gripping and pulling on a bike handle to place it on the central stand that was associated with acute flexion of the MCP joint ( - Fig. 1B), resulting in undue stresses on the radial collateral ligament of the MCP joint. Acute Grade I injuries are usually missed as patients ignore to report such injuries or self-medicate with over the counter analgesics for pain. This may lead to increase in injury grade following subsequent trauma, development of a chronic injury due to progressive gradual damage to the ligament, laxity of MCP joint, and chronic pain issues. Diagnosis of Grade I injuries will depend on identification of subtle clinical signs (ecchymoses, edema, and tenderness) over the joint as was seen in our patient. ${ }^{2}$ Although such injuries are best diagnosed clinically, radiological diagnosis is needed for few reasons. First, for confirmation of diagnosis and second to convince the patient of the existence of an injury so that they will adhere to a strict regimen of applying splint to the thumb for at least 4 to 5 weeks till the injury heals. ${ }^{3}$ Our patient was initially reluctant to apply splint as advised as she felt it was a minor injury but was convinced when presented with objective evidence of injury in the MRI films. MRI is preferable to X-ray for diagnosis if ligamentous injuries are suspected. Treatment consists of strict splinting for Grade I and early Grade II injuries while late Grade II and Grade III injuries will need exploration and repair of the ligamentary structures.

\author{
published online \\ November 30, 2020 \\ DOI https://doi.org/ \\ $10.1055 / \mathrm{s}-0040-1721864$ \\ ISSN 0970-0358.
}

\footnotetext{
(C) 2020. Association of Plastic Surgeons of India.

This is an open access article published by Thieme under the terms of the Creative Commons Attribution-NonDerivative-NonCommercial-License, permitting copying and reproduction so long as the original work is given appropriate credit. Contents may not be used for commercial purposes, or adapted, remixed, transformed or built upon. (https://creativecommons.org/licenses/by-nc-nd/4.0/).

Thieme Medical and Scientific Publishers Pvt. Ltd. A-12, 2nd Floor, Sector 2, Noida-201301 UP, India
} 

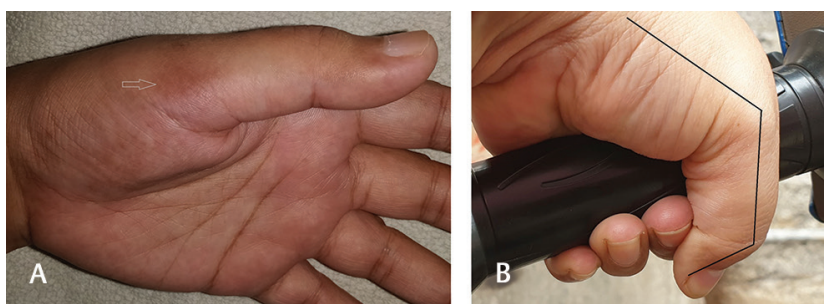

Fig. 1 (A) Edema of left thumb metacarpophalangeal (MCP) joint with ecchymosis (arrow) of the overlying skin. (B) Simulation image demonstrating acute flexion of the thumb MCP joint during certain activities resulting in acute stress injuries.

\section{Source(s) of Support}

None.

\section{Conflict of Interest}

None.

\section{References}

1 Edelstein DM, Kardashian G, Lee SK. Radial collateral ligament injuries of the thumb. J Hand Surg Am 2008;33(5):760-770

2 Tang P. Collateral ligament injuries of the thumb metacarpophalangeal joint. J Am Acad Orthop Surg 2011;19(5):287-296
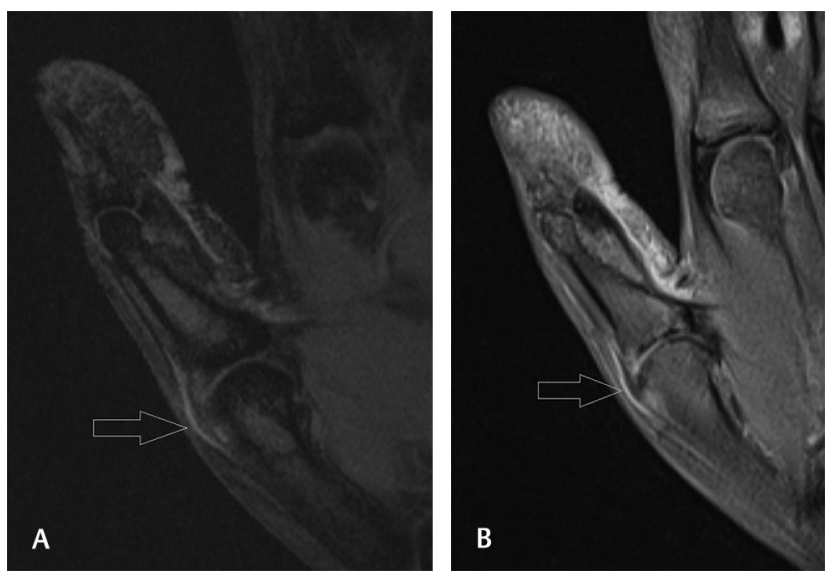

Fig. 2 Magnetic resonance imaging of left thumb with (A) fat-suppressed proton density sequence in coronal plane and (B) T2 gradient echo sequence in coronal plane showing hyperintensity in the radial collateral ligament without discontinuity in the ligament (arrows).

3 Burke F, Swindells MG, Ligamentous injuries and instability of the fingers and thumb. In: Bentley G, ed. European Surgical Orthopaedics and Traumatology. Berlin: Springer; 2014 